$10-1-2006$

\title{
Attitudes of High School Ice Hockey Players Toward Mouthguard Usage
}

\author{
Michael G. Miller \\ Western Michigan University \\ David C. Berry \\ Weber State University \\ Julia G. Tittler \\ Western Michigan University \\ Gretchen S. Gariepy \\ Western Michigan University
}

Follow this and additional works at: https://nsuworks.nova.edu/ijahsp

Part of the Medicine and Health Sciences Commons

\section{Recommended Citation}

Miller MG, Berry DC, Tittler JG, Gariepy GS. Attitudes of High School Ice Hockey Players Toward Mouthguard Usage. The Internet Journal of Allied Health Sciences and Practice. 2006 Oct 01;4(4), Article 5.

This Manuscript is brought to you for free and open access by the College of Health Care Sciences at NSUWorks. It has been accepted for inclusion in Internet Journal of Allied Health Sciences and Practice by an authorized editor of NSUWorks. For more information, please contact nsuworks@nova.edu. 


\title{
Attitudes of High School Ice Hockey Players Toward Mouthguard Usage
}

\begin{abstract}
Purpose: The purpose of this study was to examine Michigan High School ice hockey players' attitudes regarding the use of mouthguards and to determine the effects of mouthguard type, player position, education, and usage time with respect to attitudes. Methods: A questionnaire measuring players' attitudes toward mouthguards was sent to six member institutions of the Michigan State High School Athletic Association (MSHSAA) located in Southwest Michigan. Out of a total of 128 players listed on the rosters of the MSHSAA, 119 (93\%) players returned the surveys, with 117 surveys used in the analyses (91\%). Results: Approximately $25.6 \%$ of players reported wearing mouthguards $50 \%$ of the time or greater during practices and $80.3 \%$ wearing mouthguards $50 \%$ of the time or greater during games. Seventy-two percent of the subjects had never received educational information regarding mouthguards. A 2x2x3 ANOVA revealed no significant effect between player position, previous mouthguard education, and mouthguard type with respect to mouthguard attitudes. Independent t-tests revealed players wearing mouthguards greater than $50 \%$ of the time during practice and games had more positive attitudes toward mouthguards than those who wore mouthguards less than $50 \%$ of the time. Conclusion: No one specific factor affecting attitudes of mouthguard use was identified; however, the majority of the players had no previous education on mouthguard usage. Our results show a need for more educational interventional programs by healthcare providers, dentists, and coaches.
\end{abstract}




\title{
TJAHSP \\ The Internet Jourfal of Allied Health Sciences and Practice \\ http://ijahsp.nova.edu
}

A Peer Reviewed Publication of the College of Allied Health \& Nursing at Nova Southeastern University

Dedicated to allied health professional practice and education

http://ijahsp.nova.edu Vol. 4 No. 4 ISSN 1540-580X

\section{Attitudes of High School Ice Hockey Players Toward Mouthguard Usage}

\section{Michael G. Miller, EdD, ATC, CSCS 1 David C. Berry, PhD, ATC ${ }^{2}$ Gretchen S. Gariepy, MA, ATC1 Julia G. Tittler, MA, ATC 1}

\author{
1. Western Michigan University \\ 2. Weber State University
}

\section{Citation:}

Miller, M., Gariepy, G., Tittler, J., Berry, D. Attitudes of High School Ice Hockey Players Toward Mouthguard Usage. The Internet Journal of Allied Health Sciences and Practice. October 2006. Volume 4 Number 4.

\begin{abstract}
Purpose: The purpose of this study was to examine Michigan High School ice hockey players' attitudes regarding the use of mouthguards and to determine the effects of mouthguard type, player position, education, and usage time with respect to attitudes. Methods: A questionnaire measuring players' attitudes toward mouthguards was sent to six member institutions of the Michigan State High School Athletic Association (MSHSAA) located in Southwest Michigan. Out of a total of 128 players listed on the rosters of the MSHSAA, 119 (93\%) players returned the surveys, with 117 surveys used in the analyses (91\%). Results: Approximately $25.6 \%$ of players reported wearing mouthguards $50 \%$ of the time or greater during practice and $80.3 \%$ wearing mouthguards $50 \%$ of the time or greater during games. Seventy-two percent of the subjects had never received educational information regarding mouthguards. A $2 \times 2 \times 3$ ANOVA revealed no significant effect between player position, previous mouthguard education, and mouthguard type with respect to mouthguard attitudes. Independent t-tests revealed players wearing mouthguards greater than $50 \%$ of the time during practice and games had more positive attitudes toward mouthguards than those who wore mouthguards less than $50 \%$ of the time. Conclusion: No one specific factor affecting attitudes of mouthguard use was identified; however, the majority of the players had no previous education on mouthguard usage. Our results show a need for more educational interventional programs by healthcare providers, dentists, and coaches.
\end{abstract}

\section{Introduction}

Dental injuries such as lacerations, jaw fractures, and tooth fractures/avulsions are common orofacial injuries often sustained while participating in sports. In fact, Lephart and Fu estimated that 13 to $39 \%$ of all dental injuries occur as a result of some type of sports-related incident. ${ }^{1}$ However, a properly fitted and regularly used athletic mouthguard has been shown to be effective in decreasing the risk of and severity of oral-facial injuries.2,3,4 Even with this overwhelming evidence supporting the use of a mouthguard, many athletes still harbor negative feelings that ultimately influence their attitudes and usage rates toward mouthguards.

Some researchers suggest that an athlete's negative attitude toward using a mouthguard may be related to a lack of clear communication and proper educational training on how to properly use a mouthguard. For example, Hawn, Visser, and Sexton found only $11 \%$ of certified athletic trainers (ATC) and 35\% of coaches encouraged collegiate ice hockey players to use mouthguards consistently. ${ }^{5}$ A similar study examining collegiate ice hockey players found that $26 \%$ of players studied reported receiving no type of formal educational training regarding the proper use of mouthguards. ${ }^{6}$ Another study found only $13 \%$ of coaches provided some form of educational training on the importance of using mouthguards, while a final study reported that $75 \%$ of players' parents never received formal training or lacked adequate knowledge concerning the care, maintenance, and usage of mouthguards. 7,8

Athletes' attitudes and their compliance toward wearing a mouthguard are influenced by a variety of factors that include but are not limited to mouthguard comfort (e.g., speech, breathing), enforcement of the device, esthetics, and the mental perception of how a mouthguard affect an athlete's image (e.g. toughness, social acceptance).6,9-11 For some athletes, the choice to play without facial protection, whether it is a facemask or mouthguard, is viewed as a sign of toughness and courage, feelings of invulnerability, and/or simply a lack 
of consistent enforcement and education by healthcare professionals, coaches, parents, and/or referees. ${ }^{12}$ The type of mouthguard worn and the athlete's sport position may also influence an athlete's attitude and usage rates. For example, a study of collegiate ice hockey players found that defensive players wearing custom fitted mouthguards had more positive attitudes towards mouthguards compared to defensive players wearing prefabricated mouthguards. ${ }^{6}$

Research examining National Collegiate Athletic Association (NCAA) Division I ice hockey players found $52 \%$ of players wore a mouthguard during competition, while $13 \%$ of the ice hockey players in Central Collegiate Hockey Association (CCHA) wore a mouthguard more than $50 \%$ of the time during games even though the NCAA mandates the use a mouthguard.5,6 The Michigan High School Athletic Association (MHSAA) also mandates the use of mouthguards during practice and competition; however, previous research examining high school athletes' mouthguard attitudes and usage rates are limited to sports such as football, basketball, soccer, wrestling, and judo. A review of literature revealed no previous research examining high school ice hockey players' usage rates or attitudes toward mouthguards. Therefore, the purpose of this study was to examine Michigan High School ice hockey players' attitudes regarding the use of athletic mouthguards and to determine the effects of mouthguard type, player position, education, and usage time with respect to attitudes.

\section{Methods \\ Subjects}

The population selected for our study was high school aged ice hockey players from the Michigan High School Athletic Association during the 2005-2006 seasons. Twenty five schools were contacted and six (24\%) agreed to participate in the study. The certified athletic trainer or head coach at the participating schools agreed to send us a team roster and distribute and collect our questionnaires. The six rosters identified 128 athletes;
119 questionnaires were returned, with 117 (91\%) of these questionnaires usable in the data analysis.

\section{Instrumentation and Measurement}

To obtain information relative to our purpose, we examined the following research databases: CINAHL (1982-present), Health Source: Nursing/Academic Edition (1975-present), and MEDLINE (1966-present). Keyword and keyword combinations used in the search included: mouthguard(s), intraoral device(s), physical characteristics, attitudes, beliefs, and orofacial injury rates. We modified the Athletic Mouthguard Attitude Questionnaire, a 3-section questionnaire measuring athletes' usage rates, trends, and attitudes towards mouthguards, to reduce the number of questions to increase compliancy for the age population solicited. 6 Section 1 of the questionnaire identified basic subject demographic information. Section 2 measured subjects' mouthguard usage rates, current mouthguard used, and whether players ever received any type of formal education related to the proper use of a mouthguard. A discrete categorical response $(0 \%, 25 \%, 50 \%, 75 \%$, and $100 \%$ ) was used to assess the subjects' approximate percentage of time mouthguards were worn during ice hockey practices and games.

The questionnaire's final component attempted to measure subjects' attitudes towards mouthguards (Table 1). The questionnaire utilized Likert item response categories ranging from "strongly agree" to "strongly disagree." Following the recommendations of previous research, positively stated Likert items received 5 points for a response of "strongly agree" and 1 point for "strongly disagree."13 Negatively worded items were scored in reverse, with 1 point for a response of "strongly agrees and 5 points for "strongly disagrees." The highest score for the Modified Athletic Mouthguard Attitude Questionnaire was $55(5 \times \mathrm{N})$, indicating a strongly positive attitude. The lowest possible score, indicating a strongly negative attitude was $11(1 \mathrm{XN})$. A neutral attitude was scored as $33(3 \times N)$.

Table 1. The Modified Athletic Mouthguard Attitude Questionnaire.

\begin{tabular}{|l|l|}
\hline 1. & I feel wearing a mouthguard limits my playing ability. \\
\hline 2. & I feel mouthguards are bulky. \\
\hline 3. & I feel that a mouthguard limits the amount of air that I am able to breath. \\
\hline 4. & I feel my coaches have encouraged me to wear a mouthguard during athletic participation. \\
\hline 5. & I feel that any player not wearing a mouthguard during MHSAA games should receive a minor penalty. \\
\hline 6. & I feel that referees enforce the use of mouthguards during MHSAA ice hockey games. \\
\hline 7. & I feel that mouthguards protect my mouth and teeth during athletic participation. \\
\hline 8. & I would be willing to participate in athletics without my mouthguard. \\
\hline 9. & I would be unwilling to return to play without a mouthguard after sustaining an injury to my face or teeth. \\
\hline 10. & I feel that altering a mouthguard to fit better is an acceptable practice. \\
\hline 11. & I feel that wearing a mouthguard decreases my level of toughness. \\
\hline
\end{tabular}


Validity and Reliability

A previous reliability analysis conducted on the Athletic Mouthguard Attitude Questionnaire demonstrated adequate internal consistency between items. A reliability analysis on the Modified Athletic Mouthguard Attitude Questionnaire was run to examine internal consistency between the items. A Cronbach's alpha of .62 for the total attitudinal score demonstrated fair internal consistency. Nunnally and Bernstien consider an alpha equal to or greater than 0.70 to be satisfactory in demonstrating adequate internal consistency between items. Some possible explanations for the low alpha are the small sample size, age of the population solicited, and variations in the reported results from the subjects. ${ }^{14}$

\section{Data Collection}

Questionnaire packages, including a cover letter explaining the study's purpose, directions, and research participation forms were mailed to the certified athletic trainers or coaches between December 2005 and February 2006. The completion and return of the questionnaires indicated that each participant had read and/or had the purpose and study requirements explained and agreed to participate in the study. Approval for the study was granted from the supporting institution's Human Subjects Institutional Review Board.

\section{Statistical Analysis}

Means and standard deviations were calculated for the player's age, years wearing a mouthguards, and attitudes towards mouthguards. A $2 \times 2 \times 3$ analysis of variance (ANOVA) investigated the main effects and interactions between player position (offensive vs. defensive players), previous mouthguard education (yes, meaning the subject had received instructions regarding mouthguard usage vs. no, the subject never received instructions on mouthguard use), and mouthguard type (stock, mouth fitted vs. custom-fabricated) with respect to mouthguard attitudes. Post-hoc analysis using multiple pairwise comparisons based on a $t$-statistic adjusted with a Sidak correction procedure was used when there was significance.

Independent $t$-tests were used to determine differences in mouthguard attitudinal scores across groups defined by the players' reported mouthguard usage time during practices and games (wearing mouthguards $<50 \%$ and $\geq 50 \%$ of the time). All statistical testing was two-tailed with the level of statistical significance set a-priori at $p<$ 0.05. The Statistical Package for Social Sciences (version11.0, SPSS, Inc., Chicago, IL) was used to calculate the statistics.

\section{Results}

One hundred and nineteen (92\%) players responded to the questionnaires with $117 \quad(91 \%)$ usable questionnaires. Two (1\%) questionnaires were returned blank or section 3 was not completed appropriately. The average age of MHSAA players was $16.54 \pm .92$ with players averaging $10.01 \pm 3.73$ years wearing mouthguards. Thirty-nine percent $(n=45)$ of the subjects played in a defensive position, while $61 \%(n=72)$ played an offensive position.

A majority of the players $(62 \%, n=72)$ wore mouth fitted (boil and bite) mouthguards, while $27 \%(n=31)$ and $12 \%$ $(n=14)$ wore stock and custom fabricated mouthguards respectively. During practice, $26 \%(n=30)$ of the players reported wearing a mouthguard $50 \%$ of the time or greater, while $80 \% \quad(n=94)$ reported wearing a mouthguard $50 \%$ of the time or greater during ice hockey games (Table 2).

Table 2. Mouthguard Utilization According to Player Position During Practices and Games.

\begin{tabular}{|c|c|c|c|c|c|}
\hline & & \multicolumn{4}{|c|}{ Proportion of Time Used } \\
\hline $\begin{array}{l}\text { Player } \\
\text { Position }\end{array}$ & $0 \%$ & $25 \%$ & $50 \%$ & $75 \%$ & $100 \%$ \\
\hline & & \multicolumn{4}{|c|}{ Practice $(\mathrm{n}=117)^{\star}$} \\
\hline Defensive & 24 & 6 & 4 & 5 & 6 \\
\hline Offensive & 39 & 18 & 4 & 6 & 5 \\
\hline & & \multicolumn{4}{|c|}{ Games $(n=117)^{\star}$} \\
\hline Defensive & 5 & 2 & 10 & 10 & 18 \\
\hline Offensive & 1 & 15 & 10 & 17 & 0 \\
\hline
\end{tabular}

${ }^{*}$ Scores are reported as frequencies.

Seventy-four percent $(n=87)$ of the players reported altering their mouthguard to obtain a better fit, while $58 \%$ of the players were not influenced by the cost of the mouthguard. Seventy-two percent $(n=84)$ of the players reported never receiving educational information/training regarding the use of a mouthguard, while $48 \%$ of those receiving information did so from a health care provider. The remaining players received information from 
coaches/administrators (32\%), family and friends (10\%), and other individuals (10\%).

The mean attitudinal score was $31.25( \pm 5.39)$, indicating an overall negative attitude toward mouthguards. By player position, the defensive players' mean attitudinal score was $31.42( \pm 5.29)$, while the offensive players' mean attitudinal was 31.15 ( \pm 5.49 ). Both player position scores indicted an overall negative attitude towards mouthguards. An examination of the barriers influencing these negative mouthguard attitudes revealed that $75 \%$ of players agreed or strongly agreed that mouthguards are uncomfortable. When asked about the impact of a mouthguard on a player's ability to breathe, $68 \%$ respectively agreed or strongly agreed that a mouthguard does limit the ability to breathe. Considering these factors, only $32 \%$ of the players agreed or strongly agreed that the ability to play was affected while wearing a mouthguard. However, $74 \%$ players would be willing to participate in ice hockey without a mouthguard, while $54 \%$ believe that a player should not receive a minor penalty for not wearing the mandatory protective device.

A $2 \times 2 \times 3$ ANOVA revealed no significant main effect or interaction between, player position, mouthguard type, and previous mouthguard education with respect to mouthguard attitudes. Independent $t$-tests $(t(115)=$ 3.058, $P<0.05)$ revealed players wearing mouthguards $50 \%$ of the time or greater while practicing $(33.76 \pm 5.33)$ had more positive attitudes towards mouthguards compared to players wearing mouthguards less than $50 \%$ of the time $(30.39 \pm 5.17)$. An independent $t$-tests $(t(1115)=-2.931, P<0.05)$ also revealed more positive attitudes for players wearing mouthguards $50 \%$ of the time or greater during games ( $31.93 \pm 5.36$ ) compared to players wearing mouthguards less than $50 \%$ of the time $(28.39 \pm 4.62)$.

\section{Discussion}

Research studies examining the use of athletic mouthguards has been conducted at various levels in a variety of sports. ${ }^{1,5,6,15-20}$ One commonality shared between all of these studies is the belief that when worn correctly, mouthguards significantly reduce the amount and severity of orofacial injuries during athletic competition. Although the results of these studies demonstrated that mouthguards protect against orofacial injuries, most players still did not wear them on a continuous basis during competition and/or practices. $1,5,6,15-20$ This concept was further reinforced in our study.

Of those surveyed in our study, $27 \%$ of players wore a mouthguard during ice hockey practice at least half of the time. During ice hockey games, $80 \%$ of players wore a mouthguard at least $50 \%$ of the time. The high school players in our study were more compliant when it came to following the State's mouthguard rules compared to the collegiate ice hockey players in the Central Collegiate Hockey Association (CCHA). ${ }^{6}$ Previous research reported that $3.8 \%$ of ice hockey players in the CCHA wore a mouthguard $50 \%$ of the time or more during practices, while only $13 \%$ reported wearing a mouthguard $50 \%$ of the time or more during games. ${ }^{6}$ These significant differences may stem from better communication between the coaches and/or healthcare providers and the athletes in the high school setting compared to the collegiate environment. Hawn et al5 found that only $43 \%$ of coaches and athletic trainers involved in all levels of NCAA ice hockey enforced the NCAA mouthguard rule. Thus, the differences found between high school and collegiate level players could be attributed to decreased enforcement of the rules at the collegiate level.

We found that $78 \%$ of the players reported having no previous formal or informal education or training regarding how to use and properly maintain a mouthguard. This result is much higher than the findings of Berry, Miller, and Leow 6 who reported that $25 \%$ of CCHA ice hockey players never received educational information or training. The lack of proper education from trained professionals forces athletes to rely on inaccurate information and/or biased-negative opinions from teammates, coaches, or parents regarding the use of a mouthguard. Thus, it is no wonder that $74 \%$ of the players in our study reported a willingness to participate in competitive ice hockey without wearing a mouthguard.

Past research examining freshman football players at the University of Michigan found that the greatest influence on wearing mouthguards is from the coach. ${ }^{21}$ In fact, the coach's influence on mouthguard utilization was more influential than the players' own risk of being injured. Increased educational awareness of both coach and athlete has the potential to raise the player compliancy regarding mouthguard usage during practices and/or competition. Parents also play a major role in player complicacy and attitude. In a study of 1800 parents, the researchers found $76 \%$ of parents received no previous information or training about the proper use of a mouthguard. ${ }^{8}$ Educating parents about the benefits of wearing an athletic mouthguard may increase the likelihood that they will educate their own children about the importance of wearing a mouthguard and enforce its use while competing (Table 3 ). 
Table 3. Topic Areas to be Addressed in a Mouthguard Educational Intervention Program

\begin{tabular}{|l|l|}
\hline 1. & $\begin{array}{l}\text { Define what a mouthguard is and examine the different types of mouthguards including stock, mouth fit, } \\
\text { and custom fitted (vacuum and pressure laminated). }\end{array}$ \\
\hline 2. & Discuss how a mouthguard functions to reduce the risk of orofacial trauma and concussions. \\
\hline 3. & Discuss how a health care provider designs, molds, and fits a mouthguard. \\
\hline 4. & $\begin{array}{l}\text { Discuss some of the common misconceptions regarding use of a mouthguard (i.e. impairs breathing, } \\
\text { cannot talk properly). }\end{array}$ \\
\hline 5. & Discuss how to properly maintain a mouthguard. \\
\hline 6. & Discuss how to recognize when a mouthguard should be replaced. \\
\hline 7. & Discuss attitudes and perceptions of players who wear mouthguards. \\
\hline
\end{tabular}

The mean attitudinal score of our study demonstrated an overall negative attitude towards mouthguard use with no significant differences between offensive and defensive player positions. This differs from previous research which found defensive ice hockey players possessed more negative attitude toward mouthguards usage than offensive players. ${ }^{6}$ The authors believed these results stemmed from the defensive players requirement to verbalize more with players during a game and their perceived role as "enforcers" in which wearing mouthguards shows weakness. The results of our study also suggest that the players' negative attitudes are related more to mouthguard comfort and fit. This finding supports past research where players were more likely to wear a mouthguard that was softer, more durable, and more comfortable. 15

We found that $54 \%$ of players in our study did not believe they should receive a minor penalty for not wearing a mouthguard during competition. Conversely, Berry, Miller and Leow ${ }^{6}$ found that $75 \%$ of CCHA ice hockey players thought it was important for coaches and referees to enforce the use of a mouthguard during competition. Several possible reasons for high school ice hockey players' attitudes toward limited penalty enforcement include a lack of current enforcement by officials, coaches, and parents, improper educational intervention programs regarding the benefits of mouthguards, and improperly fitted mouthguards affecting players' comfort and ability to breath.

Seventy four percent of the players in our study reported altering a mouthguard in order to obtain a better fit. The majority of our players $(75 \%)$ believe mouthguards are uncomfortable, while $68 \%$ felt they limit the ability to breathe. In contrast, only a small portion of players $(31 \%)$ felt their ability to play was affected while wearing a mouthguard. Other researchers found that rugby players did not wear mouthguards because of the lack of comfort, limited breathing ability, and poor speech.22-23 Francis and Brasher24 tested three different types of mouthguards in order to examine the effects of the mouthguard on air flow and breathing. They concluded that although mouthguards may be uncomfortable and restrict forced expiratory air flow, they did appear to be beneficial in improving ventilation and economy.

\section{Conclusion}

The purpose of this study was to examine Michigan High School ice hockey players' attitudes regarding the use of athletic mouthguards and to determine the effects of mouthguard type, player position, education, and usage with respect to attitudes. We found only a limited number of players wore a mouthguard on a regular basis at least during practice, and this may be attributed to a lack of proper education about the importance of, care, maintenance, and usage of a mouthguard. Educational intervention programs on the importance of utilizing a mouthguard should be the major impetus for further research. We feel proper educational programs instituted by healthcare providers, coaches, and parents on the proper care, maintenance, and usage of a mouthguard will increase the number of athletes wearing mouth protection regularly. In addition, parents, coaches, officials, and healthcare providers need to stress the importance of properly wearing a mouthguard during all athletic participation and enforce the rules already set into place in the prevention of orofacial injuries.

\section{References}

1. Lephart SM, Fu FH. Emergency treatment of athletic injuries. Dent Clin North Am. 1991;35 (4): 707-17.

2. Flanders RA, Bhat M. The incidence of oro-facial injuries in sports: a pilot study in Illinois. J Am Dent Assoc. 1995;126:491-496.

3. McNuttly T, Shannon SW, Wright JT, Feinstein RD. Oral trauma in adolescent athletes: a study of mouth protectors. Pediatr Dent. 1989;11:209-13.

4. Garen MW, Merkle A, Wright JT. Mouth protectors and oral trauma: a study of adolescent football players. J Am Dent Assoc. 1986;112:663-5.

5. Hawn KL, Visser MF, Sexton PJ. Enforcement of mouthguard use and athlete compliance in national collegiate athletic association men's collegiate ice hockey competition. J Athl Train. 2002; 37(2):204-08.

6. Berry DC, Miller MG, Leow W. Attitudes of central collegiate hockey association ice hockey players toward athletic mouthguard use. J of Public Health Dent . 2005; 65(2):71-75. 
7. Berg R, Berkey DB, Tang MW, Altman DS, Londeree KA. Knowledge and attitudes of Arizona high-school coaches regarding oral-facial injuries and mouthguard use among athletes. J Am Dent Assoc. 1998;129:1425-1432.

8. Diab N, Mourino A. Parental attitudes toward mouthguards. Pediatr Dent. 1997;19:455-460.

9. Ranalli DN, Lancaster DM. Attitudes of college football officials regarding NCAA mouthguards regulations and player compliance. J of Public Health Dent. 1993;53:96-100.

10. Ranalli DN, Lancaster DM. Attitudes of college football coaches regarding NCAA mouthguard regulations and player compliance. J Public Health Dent. 1995;55:139-142.

11. Amis T, DiSomma $E$, Bacha $F$, Wheatley J. Influence of intra-oral maxillary sports mouthguards on the airflow dynamics of oral breathing. Med Sci Sports Exerc. 2000; 32(2):284-90.

12. Stuart MJ, Smith AM, Malo-Ortiguera SA, Fischer TL, Larson DR. A comparison of facial protection and the incidence of head, neck, and facial injuries in junior A hockey players: A function of individual playing time. Am J Sports Med. 2002;30(10):39-44.

13. Muller DJ. Measuring social attitudes: a handbook for researchers and practitioners. New York: Teachers College Press; 1986.

14. Nunnally JC, Bernstien IH: Psychometric theory. 3rd ed. New York: McGraw-Hill; 1994.

15. Gardiner DM, Ranalli DN. Attitudinal factors influencing mouthguard utilization. Dental Clinics of North America. 2000; 44(1): 53-65.

16. Lahti H, Sane J, Ylipaavalniemi P. Dental injuries in ice hockey games and training. Med Sci Sports Exerc. 2002; 34(3):400-02.

17. Sane J, Ylipaavalniemi P. Dental trauma in contact team sports. Endod Dent Traumatol. 1988; 4(4):164-69.

18. Labella CR, Smith BW, Sigurdsson A. Effect of mouthguards on dental injuries and concussions in college basketball. Med Sci Sports Exerc. 2002;34(1):41-44.

19. Padilla R, Dorney B, Balikov S. Prevention of oral injuries. J Calif Dent Assoc. 1996; 24(3):30-36.

20. Winters JE. Commentary: Role of properly fitted mouthguards in prevention of sport-related concussion. $J$ of Ath/ Train. $2001 ; 36(3): 339-41$.

21. Godwin WC, Bagramian RA, Robinson E. The utilization of mouth protectors by freshman football players. J Public Health Dent. 1972;31:22-24.

22. Chapman PJ. Players' attitudes to mouthguards and prevalence of orofacial injuries in the 1987 U.S. Rugby Football Team. Am J Sports Med. 1989;17:690-692.

23. Chapman PJ. Orofacial injuries and international rugby players' attitudes to mouthguards. Br J Sports Med. 1990;24:156-158.

24. Francis KT, Brasher J. Physiological effects of wearing mouthguards. Br J Sp Med. 1991;25(4):227-231. 